\title{
Racionalidad de la profilaxis ocular de la oftalmia neonatal en el recién nacido
}

\author{
Rationale of ocular prophylaxis of neonatal ophtalmia in the newborn infant
}

E xiste preocupación en el Comité Consultivo de Infecciones Neonatales (CCIN) de la Sociedad Chilena de Infectología (SOCHINF), respecto al enfrentamiento a nivel país de la profilaxis ocular de la oftalmía neonatal como parte de la atención inmediata del recién nacido $(\mathrm{RN})$.

La oftalmía neonatal es un cuadro clínico que se caracteriza por una conjuntivitis mucopurulenta diagnosticada durante las cuatro primeras semanas de vida. El término fue usado inicialmente para referirse a la infección por Neisseria gonorrhoeae y se emplea actualmente para cualquier conjuntivitis antes del mes de vida ${ }^{1,2}$.

En el siglo XIX la oftalmía gonocóccica explicaba casi $25 \%$ de los casos de ceguera en la infancia y afectaba a $13 \%$ de los RN. Históricamente el objetivo de la profilaxis instaurada por Credé en 1880 fue prevenir la oftalmía neonatal por $N$. gonorrohoeae ${ }^{1,3}$. Datos actuales en Estados Unidos de América (E.U.A.) refieren que 1\% de las oftalmías neonatales infecciosas es producida por N. gonorrhoeae, 2 a $40 \%$ por Chlamydia trachomatis y 30 a 50\% restante por Staphylococcus sp, Streptococcus sp, Haemophilus sp y otras bacterias gramnegativas ${ }^{1}$.

La oftalmía gonocóccica en etapa neonatal se presenta hasta en 30 a $50 \%$ de los hijos de madres infectadas, que nacen por vía vaginal y que no reciben el manejo preventivo apropiado. Es una de las complicaciones más temidas de la gonorrea a consecuencia del parto y puede presentarse junto a otras complicaciones, como sepsis, meningitis, osteoartritis y abscesos cutáneos ${ }^{4}$.

En Chile la infección por $N$. gonorrhoeae es de notificación obligatoria diaria (ENO) y forma parte de la vigilancia de susceptibilidad antimicrobiana del ISP, pero los informes epidemiológicos no contemplan a los RN como grupo específico ${ }^{5,6}$. Durante el año 2015, la tasa de gonorrea en Chile fue de 10/100.000 habitantes, siendo $4 \%$ de los casos notificados correspondientes a mujeres embarazadas en el período 2011-2015 . Respecto a $C$. trachomatis no existen datos nacionales dado que no existe vigilancia activa y su diagnóstico microbiológico exacto se ve dificultado porque requiere de medios de cultivos celulares no disponibles en la mayoría de los laboratorios y/o técnicas específicas de biología molecular ${ }^{7,8}$. En la Región Metropolitana y en el resto del país un número importante de hospitales no dispone de acceso universal a cultivo Thayer Martin, cultivos celulares para Chlamydia y tampoco a pruebas de amplificación de ácidos nucleicos para $N$. gonorrhoeae ni para C. trachomatis.

Para la prevención de la oftalmía gonocóccica, la recomendación actual del CDC es la profilaxis ocular del recién nacido con ungüento oftálmico de eritromicina al $0,5 \%$ en cada ojo en la atención inmediata del RN. El nitrato de plata y el ungüento de tetraciclina no se encuentran disponibles en E.U.A. que es desde donde nace la sugerencia técnica por lo que no se recomiendan, la bacitracina no es efectiva, la povidona iodada no se encuentra suficientemente estudiada, el ungüento de gentamicina tiene altas tasas de reacciones oculares graves y no hay estudios que sustenten la real utilidad de cloranfenicol ${ }^{1,7,9}$. Respecto a la eficacia del ungüento de eritromicina para la profilaxis de la oftalmía por Chlamydia, el CDC señala que su eficacia es menos clara que para la oftalmia gonocóccica y que no elimina la colonización nasofaríngea por este agente por lo que no evita el riesgo de desarrollar una neumonía connatal ${ }^{7,10-12}$.

En ese sentido, para ambos agentes se prefiere la estrategia de tamizaje prenatal de rutina a la mujer embarazada y el tratamiento de las infecciones maternas identificadas, como medida de prevención de la infección neonatal, medida que no está implementada en nuestro país ${ }^{1,11}$.

Desde el año 2008, el Ministerio de Salud de Chile (MINSAL) plantea que la incidencia actual de oftalmía gonocóccica es baja asociado a la disponibilidad universal de tratamiento específico para la infección gonocóccica, por lo que no se justifica la profilaxis ocular universal para este agente ${ }^{13}$. En el Manual de Procedimientos para la Atención del RN del MINSAL 2013 se establece como objetivo de la profilaxis la prevención de la infección ocular bacteriana y se sugiere que esta se realice con solución salina fisiológica ( $\mathrm{NaCl} \%$ ) estéril a todos los $\mathrm{RN}$ y que el uso de ungüento de eritromicina se reserve para los hijos de madres con antecedentes, sin especificar cuále ${ }^{14}$. En la Norma de Profilaxis, Diagnóstico y Tratamiento de las Infecciones de Transmisión Sexual (ITS) del MINSAL 2016, se recomienda la realización de la profilaxis de oftalmía gonocóccica a todo $\mathrm{RN}$ con solución oftálmica de cloranfenicol al $0,5 \%$ o con ungüento de eritromicina al $0,5 \%$ en cada ojo por una vez ${ }^{15}$.

Un agente profiláctico óptimo debe cumplir con ser activo contra $N$. gonorrhoeae y $C$. trachomatis, tener bajo riesgo de selección de cepas resistentes, no producir 
conjuntivitis química, estar disponible en presentaciones individuales y ser económico ${ }^{12}$. Eritromicina parece ser la mejor alternativa porque cubre ambos microorganismos $\mathrm{y}$ tiene bajo riesgo de conjuntivitis química ${ }^{12}$, pero en nuestro pais no se dispone comercialmente de la presentación en ungüento.

Así entonces, el CCIN recomienda la profilaxis ocular antimicrobiana universal en todos los $\mathrm{RN}$, en la primera hora de vida, en tanto no se instaure la pesquisa y estudio etiológico de estas infecciones con métodos diagnósticos con alta sensibilidad y especificidad que permitan realizar la pesquisa en la mujer gestante y el diagnóstico microbiológico oportuno en el RN. La vigilancia activa de esta infección y la implementación de métodos diagnósticos modernos permitirá en los servicios de salud realizar un diagnóstico precoz y oportuno de la enfermedad como también determinar su comportamiento epidemiológico real y la susceptibilidad antimicrobiana del agente causal.
Desde el CCIN, hacemos un llamado para vigilar la conjuntivitis neonatal en los diferentes servicios de salud, a mejorar el recurso diagnóstico de estas infecciones, a reinstalar la profilaxis ocular antimicrobiana como medida de profilaxis en las maternidades del país, incluido los $\mathrm{RN}$ por cesárea, en aquellos lugares donde no se hace pesquisa de la infección en la mujer embarazada $\mathrm{y}$, muy especialmente, en hijos de madre con alto riesgo (antecedente de abuso de alcohol o drogas, parejas nuevas o multiparejas durante la gestacion, antecedente de otras infecciones de transmision sexual (ITS) $)^{16}$, y a estudiar la susceptibilidad antimicrobiana a otras opciones de antimicrobianos disponibles en el país.

Comité Consultivo de Infecciones Neonatales Sociedad Chilena de Infectología

Santiago, abril de 2017

\section{Referencias bibliográficas}

1.- Moore D, MacDonald N, Canadian Paediatric Society, Infectious Diseases and Immunization Committee. Preventing ophtalmia neonatorum. Paediatr Child Health 2015; 20: (2): 93-6.

2.- Piling R, Long V, Hobson R, Schweiger M. Ophtalmia neonatorum: a vanishing disease or underreported notification? Eye 2009; 23: 1879-80.

3.- Dunn P. Dr Carl Credé (1819-1892) and the prevention ophthalmia neonatorum. Arch Dis Child Fetal Neonatal Ed 2000; 83: F158-F159.

4.- American Academy of Pediatrics. Gonococcal infections. In: Kimberlin DW, Brady MT, Jackson MA, Long SS, eds. Red Book: 2015 Report of the Committeee on Infectious Diseases $30^{\text {th }}$ ed. Elk Grove Village, IL: American Academy of Pediatrics 2015: 356-67.
5.- Cáceres K. Situación epidemiológica de Gonorrea. Chile, 2015. http://epi.minsal.cl/wpcontent/uploads/2016/09/INFORME_ANUAL_ GONORREA_2015.pdf

6.- Instituto de Salud Pública de Chile. Vigilancia de Neisseria gonorrhoeae. 2010-2016. Boletin de laboratorio y vigilancia al día 2016; 6 (12): $1-13$.

7.- CDC. Sexually Transmitted Diseases Treatment Guidelines, 2015 MMWR-RR 2015; 64: 3.

8.- Martínez M. Diagnóstico microbiológico de Chlamydia trachomatis: Estado actual de un problema. Rev Chilena Infectol 2001; 18 (4): 275-84.

9.- Hammerschlag M. Chlamydial and gonococcal infections in infant and children. Clin Infect Dis 2011; 53 (S3): S99-S102.

10.- Matejcek A, Goldman R. Treatment and prevention of ophthalmia neonatorum. Can Fam Physician 2013; 59: 1187-90.

11.- Zar H. Neonatal chlamydial infections.
Prevention and treatment. Pediatr Drugs 2005; 7 (2): 103-10.

12.- Zuppa A, D'Andrea V, Catenazzi P, Scorrano A, Romagnoli C. Ophtalmia neonatorum: what kind of prophylaxis? J Matern Fetal Neonatal Med 2011; 24 (6): 769-73.

13.- Ministerio de Salud de Chile. Manual de atención personalizada en el proceso reproductivo. MINSAL, 2008.

14.- Ministerio de Salud de Chile. Manual de Procedimientos para la Atención Inmediata del Recién Nacido en el Período Inmediato y Puerperio en Servicios de Obstetricia y Ginecología. MINSAL, 2013.

15.- Ministerio de Salud de Chile. Norma de Profilaxis, Diagnóstico y Tratamiento de las Infecciones de Transmisión Sexual (ITS). MINSAL, 2016.

16.- Ministerio de Salud de Chile. Norma conjunta de la Prevención de la Transmisión Vertical del VIH y la Sifilis. MINSAL, 2012. 